\title{
Chlamydia pneumoniae induces Alzheimer-like amyloid plaques in brains of BALB/c mice
}

\author{
C. Scott Little ${ }^{\mathrm{a}}$, Christine J. Hammond ${ }^{\mathrm{a}}$, Angela MacIntyre ${ }^{\mathrm{b}}$, \\ Brian J. Balin ${ }^{a}$, Denah M. Appelt ${ }^{b}$ ** \\ a Department of Pathology, Microbiology, and Immunology, \\ Philadelphia College of Osteopathic Medicine, 4170 City Avenue, Philadelphia, PA 19131, USA \\ ${ }^{\mathrm{b}}$ Department of Biomedical Sciences, Philadelphia College of Osteopathic Medicine, \\ 4170 City Avenue, Philadelphia, PA 19131, USA
}

Received 19 February 2003; received in revised form 25 April 2003; accepted 28 May 2003

\begin{abstract}
Amyloid deposits resembling plaques found in Alzheimer's disease (AD) brains were formed in the brains of non-transgenic BALB/c mice following intranasal infection with Chlamydia pneumoniae. The mice were infected at 3 months of age with C. pneumoniae isolated from an AD brain. Infection was confirmed by light and electron microscopy in olfactory tissues of the mice. C. pneumoniae was still evident in these tissues 3 months after the initial infection indicating that a persistent infection had been established. Amyloid beta (A $\beta$ ) 1-42 immunoreactive deposits were identified in the brains of infected BALB/c mice up to 3 months post-infection with the density, size, and number of deposits increasing as the infection progressed. A subset of deposits exhibited thioflavin-s labeling. Intracellular A $\beta 1-42$ labeling was observed in neuronal cells. Experimental induction of amyloid deposition in brains of non-transgenic BALB/c mice following infection with $C$. pneumoniae may be a useful model for furthering our understanding of mechanisms, linked to infection, involved in the initiation of the pathogenesis of sporadic AD.
\end{abstract}

(C) 2003 Elsevier Inc. All rights reserved.

Keywords: Alzheimer's disease; Amyloid; Animal model; Bacteria; Chlamydophila (Chlamydia) pneumoniae; Infection; Mouse; Non-transgenic; Olfactory; Plaque; Sporadic AD

\section{Introduction}

Alzheimer's disease is classified as two distinct forms: familial and sporadic. The defining neuropathology of both familial and sporadic $\mathrm{AD}$ includes the neuritic senile plaques (NSPs), consisting primarily of amyloid beta $(A \beta)$ protein, and neurofibrillary tangles (NFTs), the major component being modified tau protein. In general, the age of onset of the familial form precedes that of the sporadic form. The familial form of disease is due to genetic mutations at several well-characterized loci. The affected genes include the amyloid precursor protein (app), presenilin-1 ( $p s-1)$, and presenilin-2 ( $p s-2)$ [37,39]. These mutations are responsible for the over-expression or aberrant processing of amyloid precursor protein into the 40,42 , and 43 amino acid A $\beta$ peptides that deposit to form NSPs. Individuals that succumb

* Corresponding author. Tel.: +1-215-871-6164; fax: +1-215-871-6889.

E-mail address: denaha@pcom.edu (D.M. Appelt). to sporadic $\mathrm{AD}$, accounting for the vast majority of all $\mathrm{AD}$ cases, do not possess mutations in the previously mentioned genes. Expression of the $\varepsilon 4$ allele of the apoE gene is considered a risk factor for the development of sporadic $\mathrm{AD}$ [9,34]. Although risk factors have been identified, the early initiating events leading to the development of the sporadic form of $\mathrm{AD}$ have yet to be determined [22].

Previous models of Alzheimer's disease have utilized transgenic mice over-expressing the well-characterized mutants of presenilin and gene products of beta amyloid precursor protein $[12,36]$. The over-expression of amyloid results in the development of amyloid plaques in the brain, paralleling the pathology observed in familial AD [13]. The utility of the existing transgenic mouse models has been the elucidation of the mechanisms of amyloid deposition into plaques and how this deposition may lead to nerve cell damage and death. The experimental systems using transgenic mice do not address the initiating events of sporadic $\mathrm{AD}$ in which mutations of the amyloid precursor protein 
and presenilin are not present. In this regard, there must be other triggering mechanisms important in the development of the sporadic form of AD.

Infection has been implicated as a potential trigger in the initiation of sporadic AD as infectious agents such as Chlamydophila (Chlamydia) pneumoniae, herpes simplex virus-1 (HSV-1), and spirochetes have been associated with $\mathrm{AD}[3,18,29]$. In the initial report linking $C$. pneumoniae infection with $\mathrm{AD}, 90 \%$ of $\mathrm{AD}$ brains were PCR positive for $C$. pneumoniae, and the organism was detected in regions of the brain that exhibited AD pathology [3]. C. pneumoniae was shown to infect microglia, astrocytes, perivascular macrophages, and monocytes $[3,26]$. The organisms were metabolically active and could be isolated from the tissue and propagated in cells. Since the initial report identifying $C$. pneumoniae in the brains of $\mathrm{AD}$ patients [3], attempts to replicate this observation have met with mixed results. Several reports were unable to detect C. pneumoniae in archival tissue of $\mathrm{AD}$ patients $[11,30,32]$. Two of these studies utilized PCR to examine tissue that was paraffin embedded, which may not be ideal for identification of the organism [30,32]. An independent group was also able to identify $C$. pneumoniae in the brains of 18 of $21 \mathrm{AD}$ patients [27]. Similar to the initial report, tissue was frozen until prepared for DNA extraction and PCR amplification of bacterial sequences. Furthermore, a group from the Netherlands recently identified $C$. pneumoniae by immunohistochemistry in $\mathrm{AD}$ brains [31]. Thus, the inconsistencies between different groups may be due to differences in technique and handling of tissue prior to analysis.

Infections of the CNS have been shown to stimulate inflammatory responses that result in neurodegeneration [41]. Neuroinflammation has been recognized as a prominent feature in AD pathology [24]. This inflammation is thought to be associated with the processing and deposition of amyloid [23]. An inflammatory response stimulated by infection with $C$. pneumoniae could promote the aberrant processing and deposition of amyloid in the CNS.

The goal of this work was to determine whether $C$. pneumoniae infection of naive $\mathrm{BALB} / \mathrm{c}$ mice promoted damage in the brain similar to that identified in sporadic AD. Non-transgenic BALB/c mice were chosen in order to determine the ability of $C$. pneumoniae infection to induce AD-like pathology in the absence of predisposing genetic factors. BALB/c mice have been shown to be susceptible to a respiratory infection with $C$. pneumoniae and also maintain a persistent respiratory infection $[19,21,28,42]$. Although the organism has been shown to persist in the respiratory tract, persistence of $C$. pneumoniae infection in the mouse CNS has not been described. As the establishment of a persistent infection in the CNS may lead to inflammation and neurodegeneration, this study tested the hypothesis that $C$. pneumoniae infection in $\mathrm{BALB} / \mathrm{c}$ mice initiates processes that result in the development of AD-like pathology in the brain.

\section{Materials and methods}

\subsection{Propagation of Chlamydia pneumoniae}

C. pneumoniae, 96-41, was isolated from the brain following autopsy of an Alzheimer's disease patient and propagated in the HEp-2 cell line similar to the technique described for the $C$. pneumoniae respiratory isolate AR-39 [7]. For in vivo experiments, C. pneumoniae was concentrated using an established technique described previously [7]. In brief, a homogenate of $C$. pneumoniae-infected HEp-2 cells was passed through a filter membrane with a $0.8 \mu \mathrm{m}$ pore diameter to remove large particulate cellular debris and the organism was "captured" on a filter membrane with a $0.2 \mu \mathrm{m}$ pore diameter. The organism was washed from the filter with a small volume of Hanks balanced salt solution (HBSS). The quantitation of inclusion forming units was determined following infection of a HEp-2 epithelial cell line with a serial dilution of the concentrated organism. The inclusions were identified by immunofluorescence using a Chlamydia-specific antibody directly conjugated to FITC (Imagen, DAKO). Aliquots were diluted in HBSS to a working concentration for the intranasal inoculation of mice.

\subsection{Infection of mice with Chlamydia pneumoniae}

Under manual constraint, 3-month-old female BALB/c mice were inoculated with $2-4 \times 10^{4}$ inclusion forming units of the 96-41 isolate of $C$. pneumoniae diluted in 20-30 $\mu$ l HBSS into their nares. The inoculum was equally dispersed between both nostrils. Three female BALB/c mice were inoculated at 3 months of age for each timepoint and the brains were analyzed at 1-3 months post-infection. Two age- and sex-matched mice were mock infected with vehicle alone, HBSS, as a control for each timepoint.

\subsection{Immunohistochemistry}

Mice were perfusion fixed (intracardiac) with $4 \%$ paraformaldehyde followed by removal of the brain. The brains were immersed in $4 \%$ paraformaldehyde overnight followed by paraffin embedding and serial sectioning at $7-10 \mu \mathrm{m}$ thickness. Sections on Superfrost ${ }^{\circledR} /$ Plus (Fisher Scientific, Pittsburgh, PA) were deparaffinized, re-hydrated, and quenched for endogenous peroxidase activity ( $5 \mathrm{~min}$ in $3 \% \mathrm{H}_{2} \mathrm{O}_{2}$ ). Following a phosphate buffered saline (PBS) rinse at room temperature (RT), antigen retrieval in $1 \times$ citra antigen retrieval buffer (BioGenex, San Ramen, California) was performed for $30-45 \mathrm{~s}$ in a microwave. Sections were blocked in $2 \%$ fetal bovine serum (FBS)/PBS three times for 15 min each at RT. When mouse monoclonal antibodies were used, slides were blocked in M.O.M. mouse $\operatorname{IgG}$ blocking reagent (Vector M.O.M. kit, Vector Laboratories, Burlingame, CA) for $1 \mathrm{~h}$ at RT, rinsed, and incubated for 
$5 \mathrm{~min}$ in the M.O.M. blocking buffer. For all sections, the primary antibodies were incubated overnight at $4{ }^{\circ} \mathrm{C}$. The sections were rinsed in PBS three times for $5 \mathrm{~min}$ each, blocked three times for $15 \mathrm{~min}$ each in $2 \% \mathrm{FBS} / \mathrm{PBS}$, and incubated with appropriate secondary antibodies in a humidified chamber for $2 \mathrm{~h}$ at RT. The sections were rinsed with PBS three times for $10 \mathrm{~min}$ each and visualized with 3,3'-diaminobenzidine (DAB) (Sigma $F A S T^{\mathrm{TM}}$, Sigma-Aldrich, St. Louis, MO). Sections were rinsed with $d \mathrm{H}_{2} \mathrm{O}$, counterstained with Harris' alum hematoxylin (EM Sciences Harleco ${ }^{\circledR}$, EM Industries Inc., Hawthorne, NY), and mounted in either aqueous mount or in Permount ${ }^{\circledR}$ (Fisher Scientific). Sections were viewed on a Nikon Eclipse E800 microscope. Images were captured on a Spot RT camera (Diagnostic Instruments, Sterling Heights, MI) using the Image Pro Plus Phase 3 Imaging System software (Media Cybernetics, Silver Spring, MD).

\subsection{Dual labeling of GFAP and amyloid}

For dual labeling, sections were deparaffinized, rehydrated, and quenched for endogenous peroxidase activity as above. Antigen retrieval was performed, sections were rinsed three times over $5 \mathrm{~min}$, and blocked in $2 \%$ FBS/PBS three times for $15 \mathrm{~min}$ each at RT. For this procedure, all incubations of primary (1st rat anti-GFAP and 2nd rabbit anti-A $\beta 1-42$ ) and secondary antibodies (1st anti-rat HRP and 2nd anti-rabbit alkaline phosphatase) were carried out in a humidified chamber at $37^{\circ} \mathrm{C}$ for $15 \mathrm{~min}$ followed by three rinses over $5 \mathrm{~min}$. The sections were incubated with DAB for 8-10 min following incubation with the first $1^{\circ}$ and $2^{\circ}$ antibody pair and with the avidin biotin complex (ABC) reagent (Vector Laboratories) following by the second $1^{\circ}$ and $2^{\circ}$ antibody pair, and then allowed to react with the bromo-4-chloro-3-indolyl-phosphate/nitroblue tetrazolium (BCIP/NBT) (DAKO Corporation, Carpinteria, CA) for $10 \mathrm{~min}$. The sections were rinsed with $d \mathrm{H}_{2} \mathrm{O}$, counterstained with methyl green (ZYMED Laboratories Inc., San Francisco, CA), rinsed with $d \mathrm{H}_{2} \mathrm{O}$, dehydrated, and mounted with Permount. The colors of the reactive astrocytes were black or brown/black, amyloid plaques were blueish purple, and nuclei/cytoplasm were green.

\subsection{Antibodies}

For the detection of beta amyloid, the following antibodies were used: rabbit polyclonal antibodies against the carboxyl-terminal fragment of A $\beta 1-42$ (Oncogene Research Products, Boston, MA) and full length peptide of A $\beta 1-42$ (Biosource International Inc., Camarillo, CA) were used at concentrations of 2 and $0.25 \mathrm{mg} / \mathrm{ml}$, respectively, a mouse monoclonal antibody (4G8) to the amino acid 17-24 peptide of human A $\beta 1-42$ was used at a 1:500 dilution (Signet Laboratories Inc., Dedham, MA), and a rabbit polyclonal anti-A $\beta 1-40$ (Sigma-Aldrich) to the full length 1-40 peptide was used at a dilution of 1:50. For the detection of amyloid precursor protein, a rabbit polyclonal antibody was used at 1:500 (Sigma-Aldrich). For the detection of reactive astrocytes, a rat monoclonal antibody against glial fibrillary acidic protein (GFAP) was used at a concentration of $10 \mu \mathrm{g} / \mathrm{ml}$ (ZYMED Laboratories Inc.). Detection of $C$. pneumoniae used two different monoclonal antibodies: one antibody used at a concentration of $5 \mu \mathrm{g} / \mathrm{ml}$ recognized the major outer membrane protein (MOMP) (DAKO), the other recognized chlamydia lipopolysaccharide (LPS) and was used neat (Imagen, DAKO). Secondary antibodies consisted of sheep anti-mouse $\operatorname{IgG}(\mathrm{H}+\mathrm{L})$, donkey anti-rabbit $\mathrm{IgG}$ $(\mathrm{H}+\mathrm{L})$, and goat anti-rat (all were conjugated to HRP and used at dilutions between 1:200 and 1:300) (Amersham Biosciences, Piscataway, NJ and ZYMED Laboratories Inc.), and a goat anti-rabbit antibody conjugated to alkaline phosphatase was used at 1:300 (Vectastain kit, Vector Laboratories).

\subsection{Thioflavin-s staining}

The sections were stained according to a protocol published at website http://www-medlib.med.utah.edu/WebPath/ webpath.html. In brief, sections were deparaffinized, rehydrated, counterstained in Mayer's hematoxylin (Electron Microscopy Sciences, Fort Washington, PA) for $5 \mathrm{~min}$, rinsed in water for $5 \mathrm{~min}$, rinsed in $d \mathrm{H}_{2} \mathrm{O}$ and stained with $1 \%$ thioflavin-s (Sigma-Aldrich) for $5 \mathrm{~min}$, followed by differentiation in $70 \%$ alcohol for $5 \mathrm{~min}$. The sections were then mounted in glycerin jelly (http://www-medlib.med.utah.edu/ WebPath/webpath.html).

\subsection{Electron microscopy}

Samples of paraformaldehyde-fixed brain tissue, olfactory epithelia, and olfactory bulbs were immersed in $1 \%$ osmium tetroxide (Electron Microscopy Sciences) diluted in PBS for $1 \mathrm{~h}$ at RT, dehydrated in $50 \%$ ethanol for $30 \mathrm{~min}$, stained with $2 \%$ uranyl acetate (Electron Microscopy Sciences) in $50 \%$ ethanol, and dehydrated in graded ethanols followed by an overnight incubation with a 50/50 mixture of propylene oxide/epon (Electron Microscopy Sciences). Samples were embedded in epon Embed 812, sectioned on a Riechert ultramicrotome, and viewed on a Jeol 1200 EX transmission electron microscope.

\section{Results}

\subsection{Chlamydia pneumoniae is present in the olfactory tissues of infected mice}

Olfactory bulbs from infected and uninfected mice were processed for both light and ultrastructural analyses. The presence of $C$. pneumoniae antigen was detected by light microscopy using Chlamydia-specific antibodies in the olfactory tissues. The most prominent labeling was observed in 

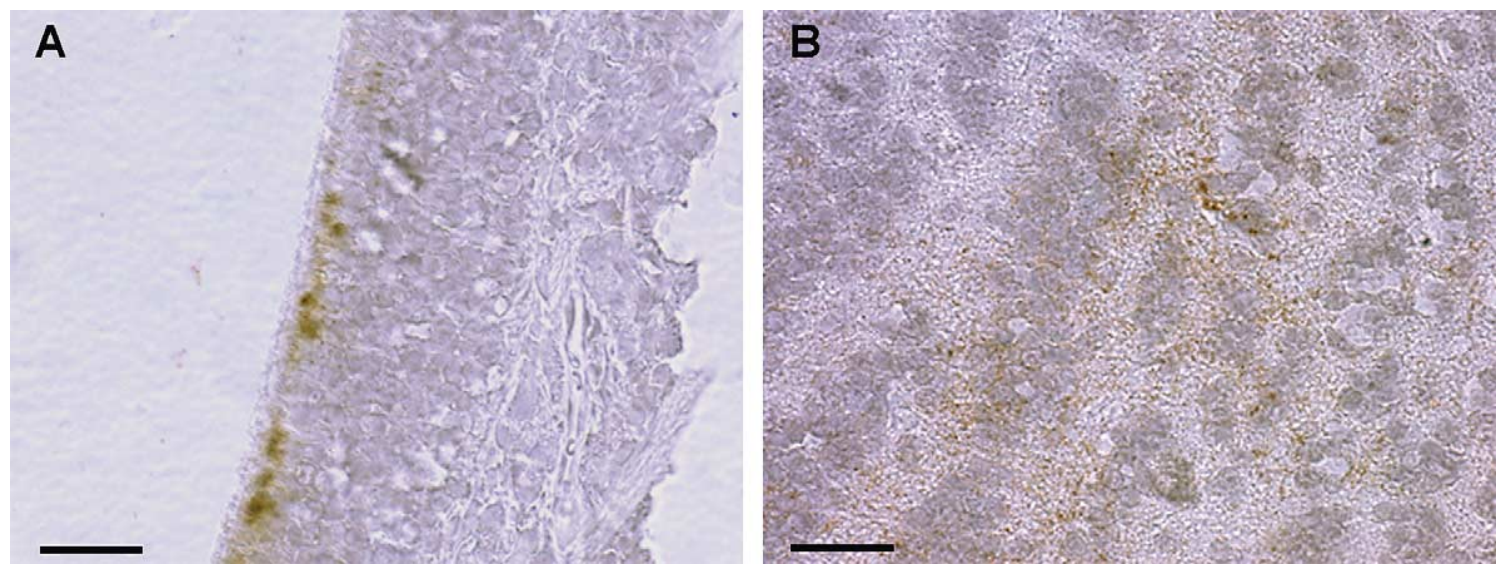

Fig. 1. Chlamydia pneumoniae antigens in the olfactory tissues of infected mice. Olfactory bulbs were examined by light microscopy for the presence of Chlamydia antigens. Representative images of Chlamydia-specific labeling in olfactory tissue are shown. Three months after intranasal inoculation, Chlamydia antigens were detected in olfactory epithelia (A) as well as the granular insular layer of the olfactory bulb (B), as observed with deposition of brown reaction product (bars $=25 \mu \mathrm{m}$ ).

olfactory epithelia (Fig. 1A) and the granular insular layer of the olfactory bulbs (Fig. 1B) of mice infected for 3 months. Chlamydial organism was identified by electron microscopy in the olfactory bulbs at 1-3 months post-infection (Fig. 2), indicating that a persistent infection had been established in the animals. Elementary body forms were identified within intracellular vacuoles. $C$. pneumoniae was not detected by either light or ultrastructural analyses in control mice.

\subsection{Mice infected with Chlamydia pneumoniae undergo amyloid deposition in the brain}

Intriguingly, the animals that had been inoculated with C. pneumoniae demonstrated A $\beta 1-42$ immunoreactive deposits at 1-3 months post-infection (Fig. 3). These deposits were immunoreactive with both monoclonal and polyclonal A $\beta 1-42$ antibodies. These extracellular deposits were not immunoreactive with antibodies specific for APP or A $\beta 1-40$ (data not shown). In the infected animals, $A \beta 1-42$ immunoreactive deposits were non-dense, predominantly diffuse, accumulations of amyloid less than $20 \mu \mathrm{m}$ in di- ameter at 1 month post-infection, and resembled immature AD plaques (Fig. 3 and Table 1). At 2 and 3 months, there was an increase in number and size of the amyloid deposits (Fig. 3 and Table 1). At 3 months post-infection, numerous $A \beta$ immunoreactive plaques in the mouse brain were observed in regions in which $\mathrm{AD}$ plaque pathology is observed in the human brain (Fig. 4). These areas included the hippocampus, the amygdala, the entorhinal cortex, the perirhinal cortex, and the thalamic regions (Fig. 5). The total numbers of A $\beta 1-42$ immunoreactive deposits increased from 7 at 1 month post-infection, to 122 at 2 months post-infection and 189 at 3 months post-infection (Table 1). With regard to size of these deposits, they range in size from less than $20 \mu \mathrm{m}(+/ \mathrm{e}$, blue dot) to greater than $70 \mu \mathrm{m}$ $(+++/ e$, red dot $)$ in diameter. The majority of deposits exceeding $20 \mu \mathrm{m}$ in diameter were observed beginning at 2 months post-infection. The mock (vehicle alone) control mice displayed only the smallest deposits of amyloid ( $20 \mu \mathrm{m}$ or less), and the number and size was not different at any of the examined timepoints (see Table 1), suggesting that $C$. pneumoniae is the stimulus for the progression of
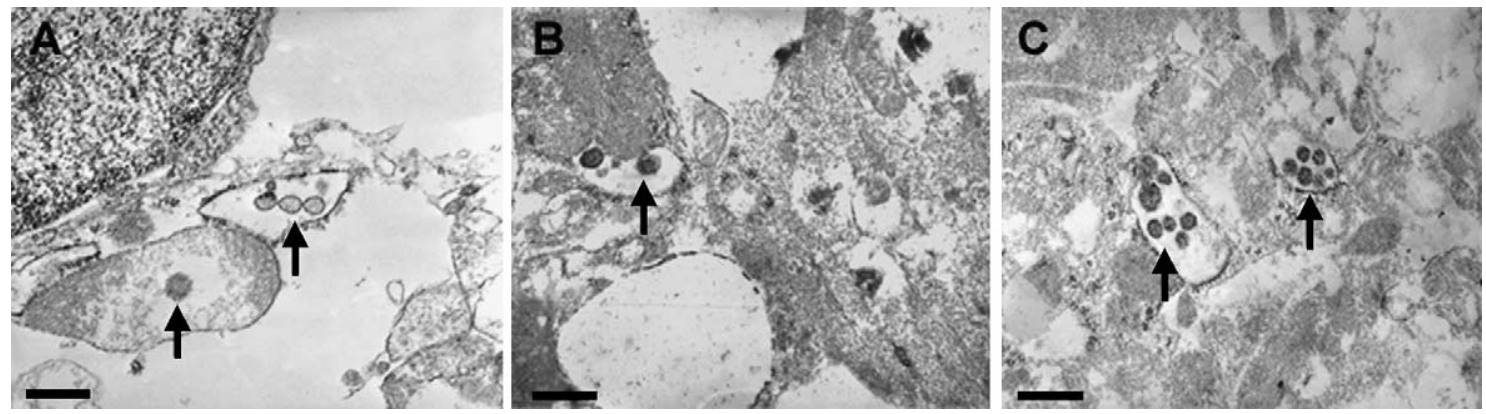

Fig. 2. Ultrastructural profiles of Chlamydia pneumoniae in the olfactory bulbs of infected mice. The olfactory bulb tissues of C. pneumoniae-infected mice were examined for the presence of the bacteria. The olfactory bulbs were examined 1 month (A), 2 months (B), and 3 months (C) following infection and elementary body forms (arrows) were identified (bars $=400 \mathrm{~nm}$ ). 

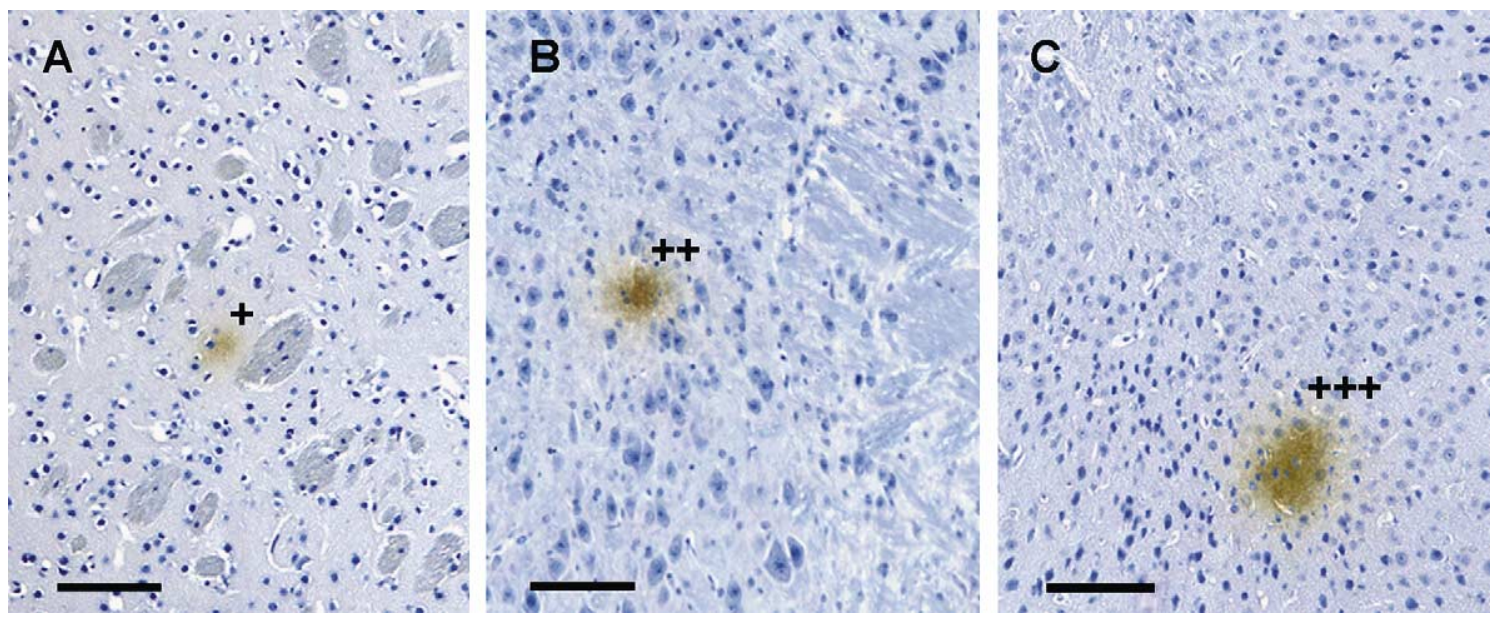

Fig. 3. Immunohistochemical analyses of $\mathrm{A} \beta 1-42$ immunoreactive deposits in the brains of mice following infection with Chlamydia pneumoniae demonstrating variable deposit sizes $(+,++,+++)$. Representative images of $A \beta 1-42$ immunoreactive deposits in the following brain regions, the caudate/putamen of 1 month infected (panel A), the red nucleus of 2 months infected (panel B), and the piriform cortex of 3 months infected mice (panel C). In panel A, bar $=80 \mu \mathrm{m}$; panels B and C, bar $=90 \mu \mathrm{m}$.

amyloid deposition in the infected animals. While focal deposits were observed in our infected animals, the extent of deposit development after 3 months may still only account for early initiation events triggered by infection with C. pneumoniae.
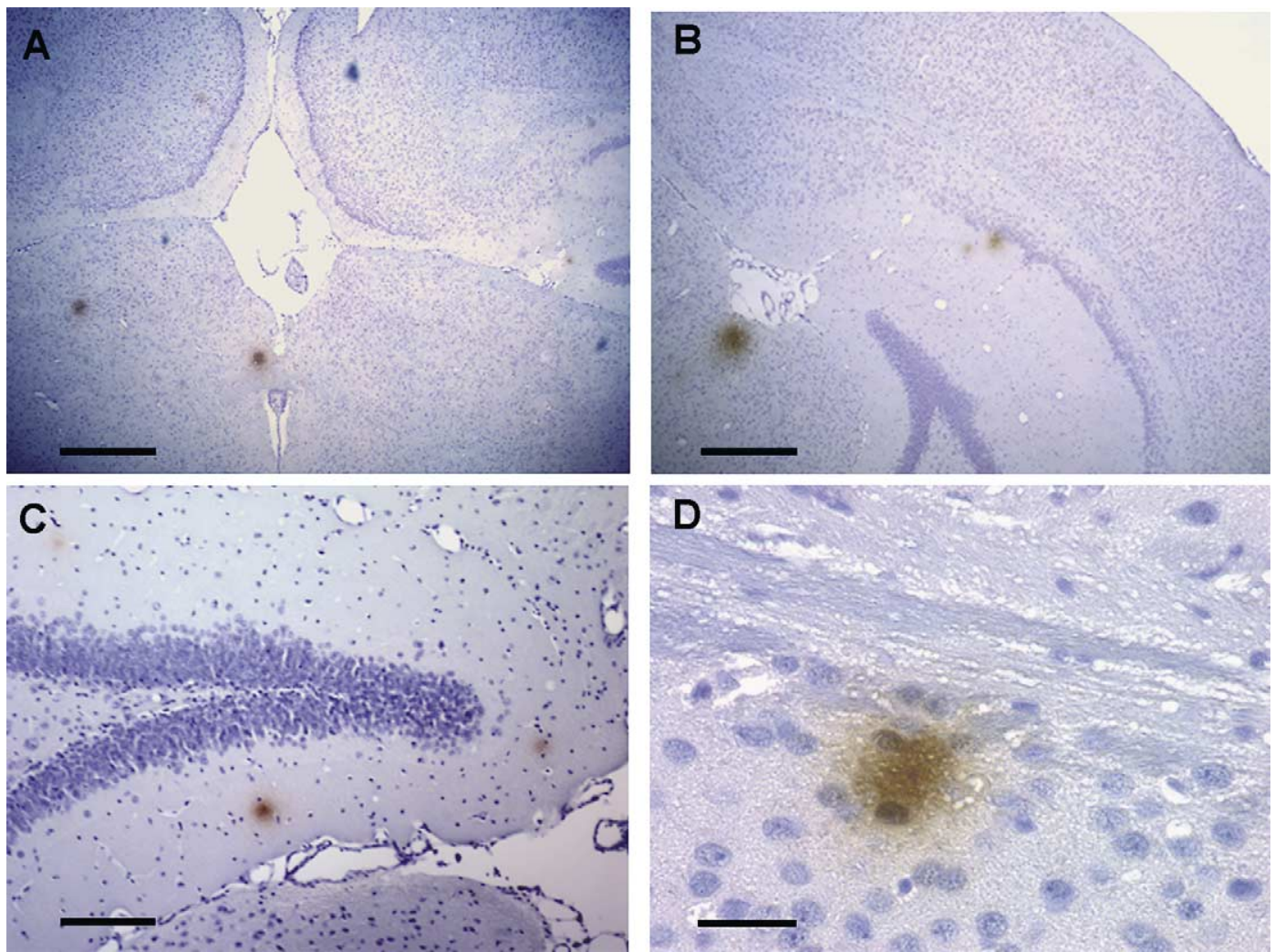

Fig. 4. Immunohistochemical analysis of the distribution of A $31-42$ deposits in the brains of Chlamydia pneumoniae-infected mice. Central and intermediate gray (panel A), superior gray and CA1 (panel B), dentate gyrus (panel C), and presubiculum (panel D). In panel A, bar $=400 \mu \mathrm{m}$; panel $\mathrm{B}$, bar $=200 \mu \mathrm{m}$; panel $\mathrm{C}$, bar $=90 \mu \mathrm{m}$; and panel $\mathrm{D}$, bar $=25 \mu \mathrm{m}$.

\subsection{Fibrillogenic amyloid deposits are present in the brains of infected mice}

As thioflavin-s is used as an indicator for the conversion of amyloid into fibrillogenic forms in $\mathrm{AD}$ plaques, we 
Table 1

The total number of A $\beta 1-42$ positive immunoreactive deposits in the brains of three C. pneumoniae infected and two uninfected (vehicle alone) control $\mathrm{BALB} / \mathrm{c}$ mice per group evaluated after 1-3 months

\begin{tabular}{|c|c|c|c|c|}
\hline & \multirow{2}{*}{ Total number } & \multicolumn{3}{|l|}{ Deposits by score } \\
\hline & & $+(\bullet$, blue dot $)$ & $++(C$, yellow dot $)$ & $+++(e$, red dot $)$ \\
\hline \multicolumn{5}{|l|}{1 month post-infection } \\
\hline Infected $(n=3)$ & 7 & 6 & 1 & 0 \\
\hline Uninfected $(n=2)$ & 6 & 6 & 0 & 0 \\
\hline \multicolumn{5}{|l|}{2 months post-infection } \\
\hline Infected $(n=3)$ & 122 & 104 & 16 & 2 \\
\hline Uninfected $(n=2)$ & 17 & 17 & 0 & 0 \\
\hline \multicolumn{5}{|l|}{3 months post-infection } \\
\hline Infected $(n=3)$ & 189 & 150 & 36 & 3 \\
\hline Uninfected $(n=2)$ & 9 & 9 & 0 & 0 \\
\hline
\end{tabular}

The A $\beta 1-42$ positive deposits were scored by color: blue, the smallest (less than $20 \mu \mathrm{m}$ in diameter); yellow, intermediate (greater than $20 \mu \mathrm{m}$ and less than $70 \mu \mathrm{m}$ in diameter); and red, the largest deposits (greater than $70 \mu \mathrm{m}$ in diameter). Representative images of A $\beta 1-42$ positive deposits are shown in Figs. 3-5.
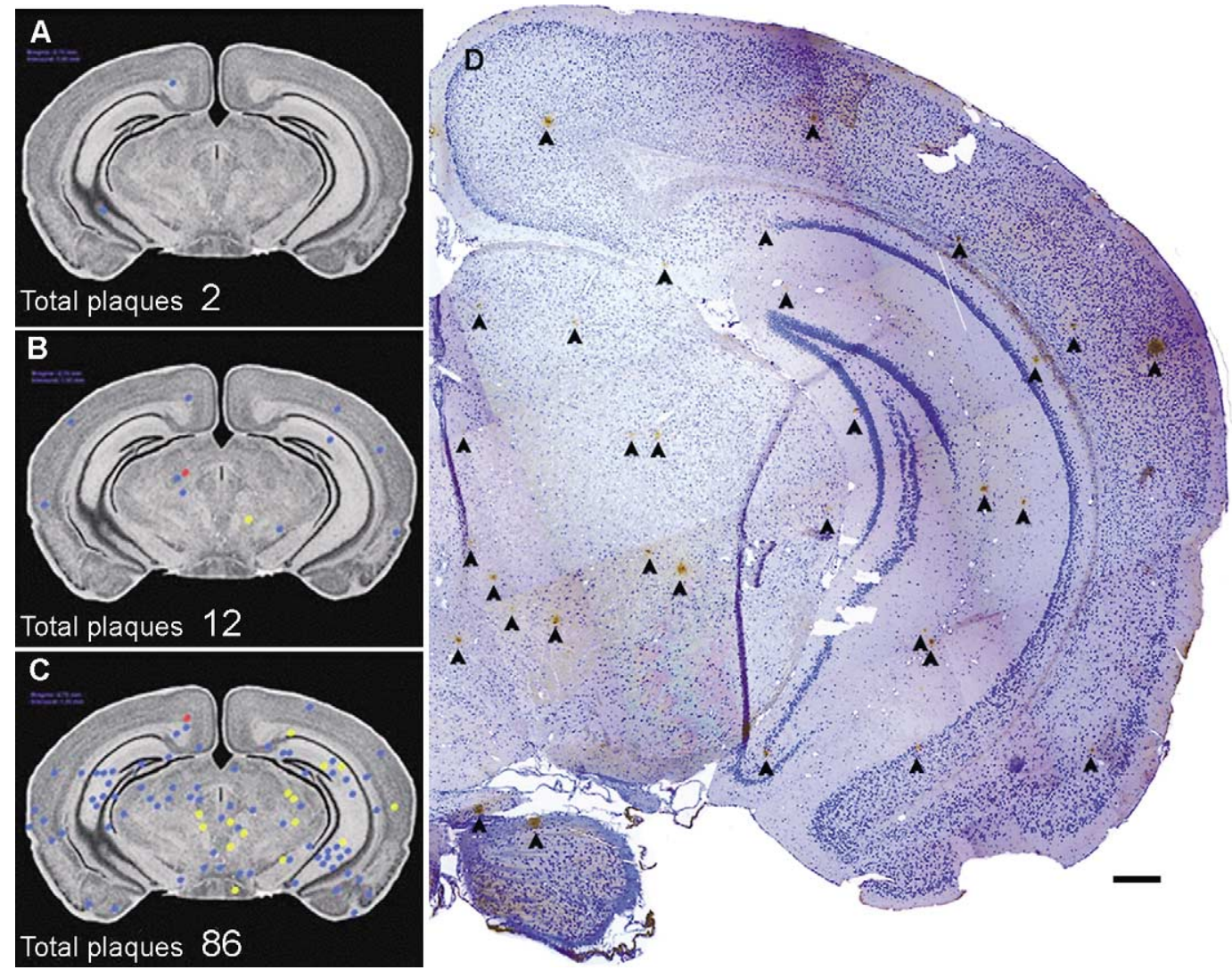

Fig. 5. The progression of A $1-42$ immunoreactivity at the level of the hippocampus following infection with Chlamydia pneumoniae. The brains of three infected mice per group showed an increased total number and size of A $\beta 1-42$ deposits as the length of infection increased (panels A-C). Deposits are distributed in widespread areas including those which typically display AD pathology such as the hippocampus, the dentate gyrus, and the amygdala. The total number of deposits in this region, represented by solid circles (blue, + ; yellow, ++ ; and red, +++ ), increased from 2 at 1 month (panel A) to 12 at 2 months (panel B) and finally 86 at 3 months (panel C). A montage of a single hemisphere illustrates A $\beta 1-42$ immunoreactive deposits (arrowheads) of a mouse brain 3 months post-infection (panel D). This montage shows extensive A $\beta$ pathology in a single 10- $\mu \mathrm{m}$ thick coronal section (bar $=200 \mu \mathrm{m}$ ). Images used in panels A-C were taken from the Mouse Brain Library (www.mbl.org) [33,38]. 

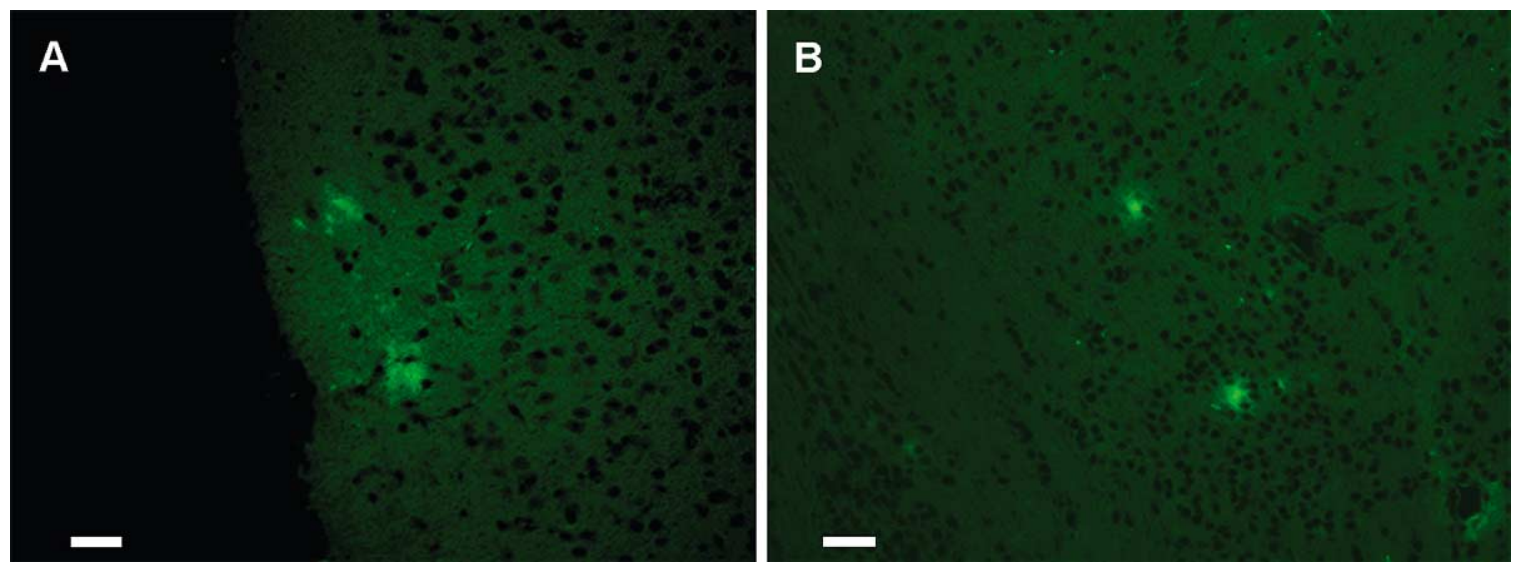

Fig. 6. Following infection with Chlamydia pneumoniae, a few amyloid deposits in the brains contained fibrillogenic amyloid. Sections demonstrating fibrillar A $\beta$ deposits were labeled with thioflavin-s (green) at 1 month (panel A) and 3 months post-infection (panel B) $($ bars $=50 \mu \mathrm{m})$.

used this to determine if amyloid deposits in the mouse brain were fibrillogenic. Our model strictly demonstrates accumulation of mouse amyloid, which normally does not deposit and/or undergo fibrillogenesis in the mouse brain. For this reason, we tested whether the A $\beta 1-42$ immunoreactive deposits of mouse amyloid displayed properties similar to mature plaques consisting of human amyloid. Thioflavin-s positive deposits were observed in the brains of C. pneumoniae-infected mice at 1-3 months post-infection (Fig. 6). Only some of the A $\beta 1-42$ immunoreactive plaques were thioflavin-s positive, indicating that a small subset of the $A \beta 1-42$ deposits were comprised of fibrillogenic forms of amyloid.

\subsection{Reactive astrocytes and amyloid deposits}

We observed reactive astrocytes, at times, in close proximity to the A $\beta 1-42$ deposits at 3 months post-infection (Fig. 7). Activated astrocytes were observed in the brains of 2 month infected mice, but not co-localized with obvious amyloid deposits. After 3 months, numerous reactive astrocytes were present (Fig. 7A) and were co-localized with some A $\beta 1-42$ deposits (Fig. 7B). Reactive astrocytes surrounded some vessels demonstrating perivascular A $\beta 1-42$ immunoreactivity, suggestive of amyloid angiopathy observed in $\mathrm{AD}$ brains (Fig. 7C). As the time of infection increased, astrocyte activation in regions with amyloid de-
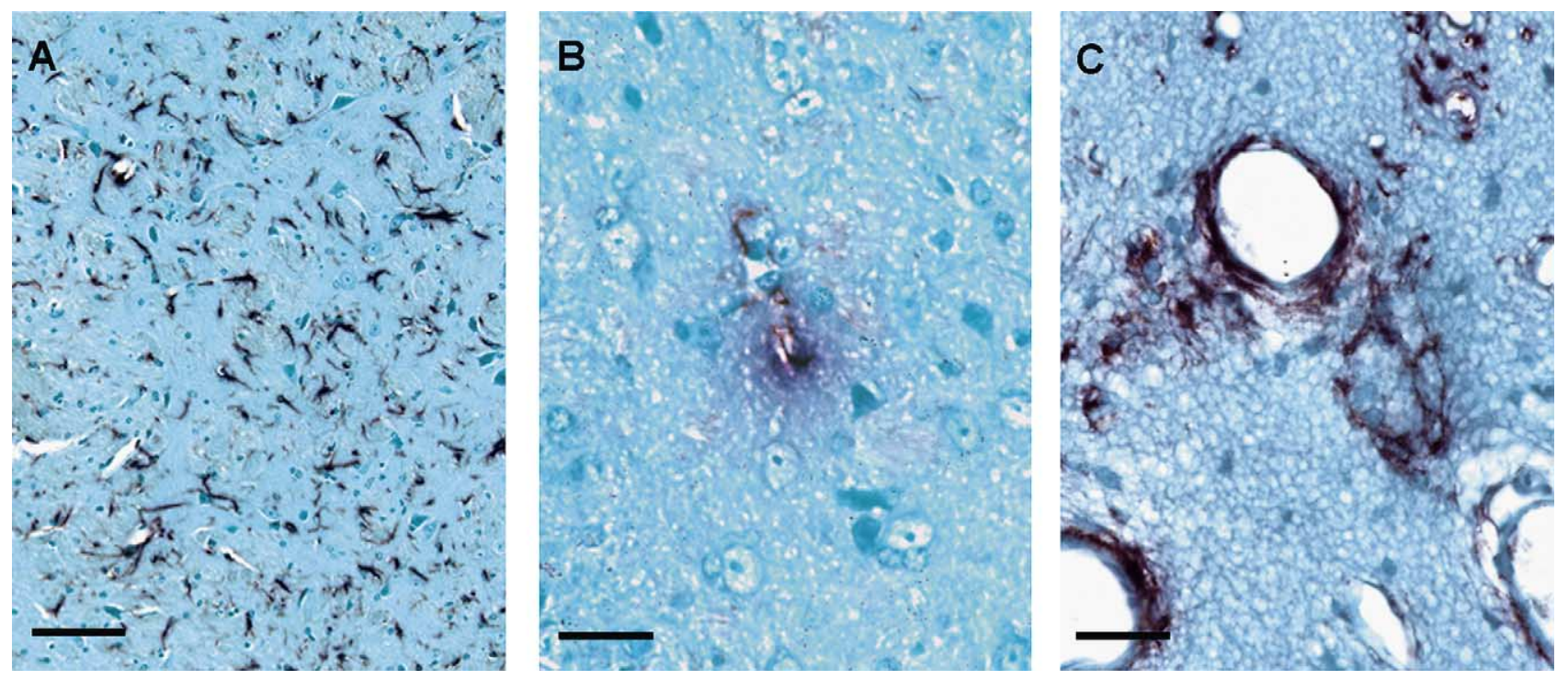

Fig. 7. Astrocyte activation and co-localization with amyloid deposits. Three months after the initial infection, numerous activated astrocytes (GFAP positive, brown/black) were observed in regions absent of obvious amyloid deposits (panel A). Astrocytes were also observed co-localized with some amyloid deposits (A $\beta 1-42$, blue/purple) (panel B), and associated with amyloid around blood vessels (panel C). In panel A, bar = 50 $\mu \mathrm{m}$; panel B, bar $=20 \mu \mathrm{m}$; and panel $\mathrm{C}$, bar $=25 \mu \mathrm{m}$. 

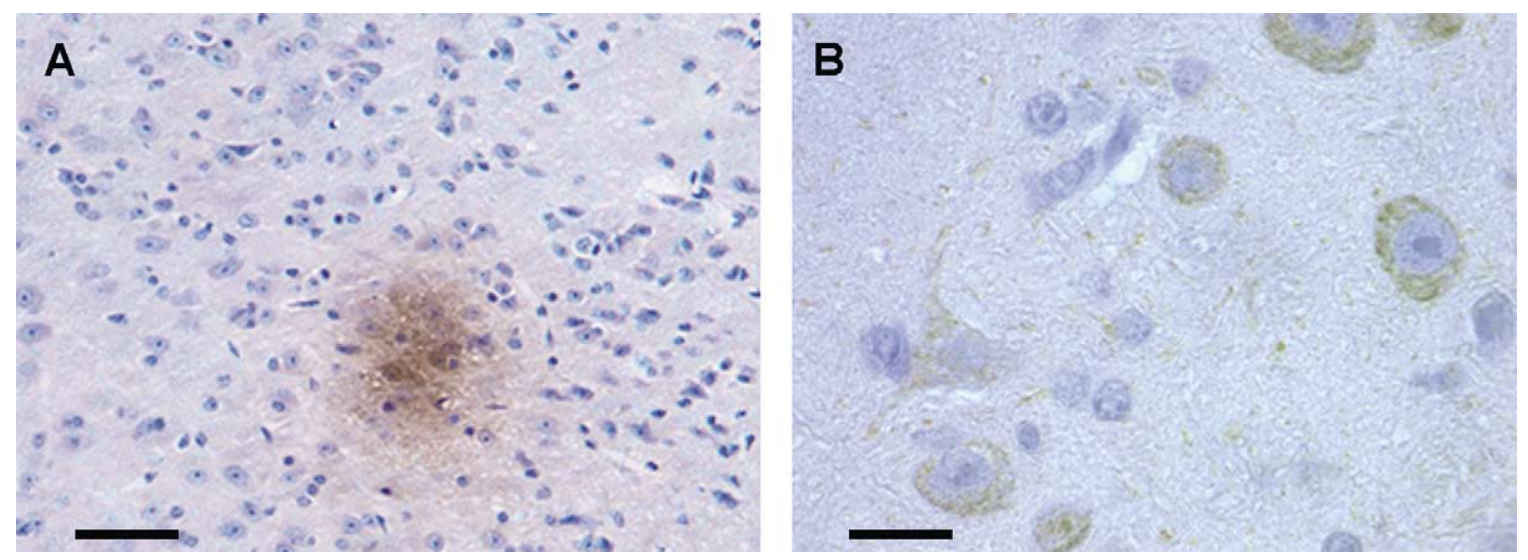

Fig. 8. Intracellular A $\beta 1-42$ immunoreactivity in the brains of mice 3 months post-infection. Note the A $\beta 1-42$ labeling (brown), both intracellular and extracellular, in the superior gray (panel A), as well as intracellular labeling of the perikaryon and processes of neuronal cells at the level of the hippocampus (panel B). In panel A, bar $=60 \mu \mathrm{m}$; panel $\mathrm{B}$, bar $=15 \mu \mathrm{m}$.

posits also increased. Some regions where the astrocytes appeared activated had no evident deposits (Fig. 7A). The activation of astrocytes without obvious amyloid deposits may be due to soluble fragments of amyloid, as these are potent stimulators of astrocyte activation [2].

\subsection{Intracellular amyloid beta $1-42$}

In addition to the extracellular deposits of $A \beta 1-42$, intracellular cytoplasmic $A \beta 1-42$ immunoreactivity was observed in the brains of infected mice at 3 months post-infection (Fig. 8). In particular, the perikaryon and cell processes of neuronal cells in the hippocampal region exhibited this labeling. In some areas of intracellular labeling, extracellular deposits of amyloid were also apparent (Fig. 8A). Discrete A $\beta 1-42$ immunoreactive extracellular fragments were also observed, suggesting that these fragments accumulate prior to the formation of a more focal deposit (Fig. 8B).

\section{Discussion}

This study has addressed the role of $C$. pneumoniae infection in the induction of amyloid deposits in non-transgenic mice. This microorganism was identified in the olfactory epithelia (chlamydial antigens) and the olfactory bulbs (chlamydial antigens and typical morphology) by both light and electron microscopy. Analysis of pathology in the brain revealed amyloid deposits that resembled amyloid plaques found in the human AD brain. Activation of astrocytes as well as co-localization of some of these reactive astrocytes with the amyloid deposits suggested that a cellular inflammatory response was initiated. This response could be due to the presence of $C$. pneumoniae or directed against amyloid deposits induced by $C$. pneumoniae infection. The induction of amyloid deposits in the brains of non-transgenic BALB/c mice supports the hypothesis that infection with $C$. pneumoniae is capable of accelerating or inducing AD-like pathology, and may be a trigger in the pathogenesis of $\mathrm{AD}$.

\subsection{Experimental models of $A D$}

The generation and accumulation of pathology in the $\mathrm{AD}$ brain occurs in a progressive fashion, with deposition of amyloid increasing with age [5]. The transgenic mouse models of AD show that amyloid deposition progressively develops throughout the mouse brain [12]. In the mouse models that express mutated human app, ps-1, or $p s-2$ genes, substantial amyloid deposition is not apparent prior to 9 months of age. The degree of amyloid deposition in our 3 month $C$. pneumoniae-infected non-transgenic BALB/c mice may reflect an early stage in the development of amyloid deposits. Given that the stimulus for amyloid processing and deposition is different between these two experimental systems, a direct comparison is not possible. Non-transgenic BALB/c mice typically do not develop amyloid pathology $[8,10]$, however following experimental induction, these mice developed deposits consisting solely of mouse amyloid. Mouse $A \beta$ is highly homologous to human $A \beta[15,20]$, but typically does not deposit into plaques. Presumably, $C$. pneumoniae infection stimulated the processing of mouse APP, resulting in fragments of amyloid that deposit and undergo conformational change into fibrillogenic forms. Although transgenic mice have been appropriate models for studying the development of amyloid pathology, due to their mutations, these models more closely align with familial AD than with sporadic AD. Our experimental model shows, that in animals with no genetic modifications, infection with $C$. pneumoniae alone was sufficient to induce AD-like pathology.

\subsection{Chlamydia pneumoniae infection}

Previous studies that investigated the role of C. pneumoniae as a respiratory pathogen used an intranasal route of 
inoculation for infection [35], as this is the natural route of infection for this obligate intracellular pathogen. In our studies, mice inoculated intranasally with $C$. pneumoniae demonstrated infection in the nasal olfactory epithelia within 1 month. The bacteria were still evident after 3 months, suggesting that a persistent infection had been established. Infection in the olfactory epithelia resulted in subsequent infection of the olfactory bulbs. Presumably, infection of the olfactory bulbs occurred via an intracellular route from the original site of infection, as ultrastructural analysis verified the presence of the organism in vacuoles within cells of the olfactory bulb. Alternatively, the organism may have trafficked to the olfactory bulbs in an extracellular fashions, as we have detected $C$. pneumoniae antigens in the interstitial spaces at the level of the granular insular layer. Either scenario could facilitate further trafficking of the organism from olfactory bulb to deeper regions of the brain.

Interestingly, the olfactory pathways and entorhinal cortex exhibit the earliest pathology in the AD brain [17]. The specific vulnerability of these pathways to pathology is not well understood. Previous study of the relationship of $C$. pneumoniae and $\mathrm{AD}$ revealed genetic material from the organism in olfactory bulbs [16]. In addition, the organism was identified in the entorhinal cortex, the hippocampus, and the temporal cortex of AD brains suggesting that the organism can traffic to these sites [3]. Analogous to the human findings, infection was confirmed in the olfactory bulbs of our experimental mice indicating that the olfactory pathway is vulnerable to infection.

Following intranasal inoculation, $C$. pneumoniae typically establishes a lower respiratory tract infection. Usually, the lower respiratory tract infection is self-limited with the host immune response resolving the infection within several weeks [35]. This was confirmed in our experiments using the 96-41 isolate of $C$. pneumoniae (unpublished observations). Therefore, mice inoculated with either a respiratory isolate or the 96-41 isolate appear to establish infection in a similar fashion.

Infection in the lung serves as a stimulus for monocyte and lymphocyte infiltration and these cells are susceptible to infection by $C$. pneumoniae $[1,4]$. C. pneumoniae may infect and utilize these host immune cells to traffic systemically to distant sites, particularly to the central nervous system. Recent studies have shown that infection of monocytic cells enhances transmigration across a human brain microvascular endothelial cell layer [25]. Infected perivascular macrophages and monocytes have been observed in and around blood vessels in AD brains [3]. Taken together, these data suggest that infection of leukocytes with $C$. pneumoniae predisposes the central nervous system (human, and potentially mouse) to infection from the systemic circulation. Although systemic infection may be an alternate route, the olfactory pathway(s) was the primary route of infection in this study.

\subsection{Amyloid deposition}

We observed amyloid deposits at 1 month after inoculation, and the amyloid deposits in the brain increased in number and size as the infection progressed. A subset of these deposits also exhibited thioflavin-s labeling, revealing the fibrillogenic nature of the amyloid in these deposits. In contrast, the deposits observed in uninfected mice that received vehicle alone were mostly small, diffuse, and few in number, representing a baseline level in uninfected mice. In addition to the amyloid deposits in the infected mice, other pathologies consistent with AD were apparent. These included the accumulation of amyloid around blood vessels, and activated astrocytes, some of which co-localized with A $\beta 1-42$ positive deposits. This may lead to amyloid angiopathy and inflammation, predisposing the brain to further damage.

The activated resident astrocytes may be responding to the amyloid deposits and/or to $C$. pneumoniae bacterial products. It has been shown previously that peripheral stimulation with LPS induced a transient increase in inflammatory cytokine mRNAs, and changes in APP isoforms in the brains of mice [6]. In addition, others have shown that bacterial LPS infused into the rat brain induces an inflammatory response as indicated by microglial reactivity and cytokine expression, characteristic of inflammation in the AD brain [14]. Therefore, we believe that soluble factors produced by C. pneumoniae, such as LPS, could influence amyloid processing at sites distal to the infected cells. Production of cytokines such as IL-1 $\beta$, TNF- $\alpha$, and IL- 6 by LPS-activated glial cells could result in the upregulation of amyloid production and processing. Although inflammation in $\mathrm{AD}$, as a result of $A \beta$ deposition, is accepted as a major mechanism in overall pathogenesis [24], C. pneumoniae infection may be an initial stimulus activating $A \beta$ processing and deposition.

Inflammation, the host response to infection with $C$. pneumoniae, may prevent or inhibit $C$. pneumoniae replication while stimulating the aberrant processing of amyloid. Although the mice appear to be asymptomatic, these mice harbor $C$. pneumoniae in olfactory tissues. It is also apparent that these mice have activated glial cells in regions of the brain where no $C$. pneumoniae has been detected. This activation may be in response to bacterial products (LPS), host factors produced in response to the infection (cytokines) or in response to the amyloid deposits. At this point, it is not clear which of these is the stimulus for continued glial activation, but this global response may prevent the spread of C. pneumoniae to deeper cortical regions.

\subsection{Neuronal intracellular amyloid}

Amyloid deposits, resulting from the processing of endogenous amyloid into $A \beta 1-42$ positive fragments, were found in much greater numbers in the infected mice as compared with the minimal number of deposits found in the vehicle-alone inoculated age-matched control mice. As intracellular A $\beta 1-42$ labeling occurs in cortical neurons, intra- 
cellular processing of amyloid into $A \beta 1-42$ may contribute to the extracellular amyloid deposition. Our findings are consistent with recent reports of intracellular processing of amyloid into $A \beta 1-42$ forms in pyramidal neurons in the entorhinal cortex of $\mathrm{AD}$ brains [10,40]. Although $C$. pneumoniae infection in cortical neurons has not been shown, chronic infection of the olfactory pathways may stimulate $A \beta$ processing and deposition at sites within the limbic pathway connected to olfaction. C. pneumoniae may exert an influence on cells within this synaptic field, presumably through a pro-inflammatory process. Thus, infection in the olfactory bulb may result in the deposition of extracellular A $\beta 1-42$ identified in the entorhinal cortex, the amygdala, and the hippocampal formation. Considering that this study was of relatively short duration, extended times of infection may be necessary for further incursion of the organism into deeper cortical structures. However, as the connectivity of the cortical structures in which we see damage is associated with olfaction, absence of the organism in these cortical structures would not preclude pathology. Given that the earlier report demonstrated the presence of $C$. pneumoniae in areas of amyloid pathology [3], it would be reasonable to look for this association in the mouse brain, in the future, following extended times of infection.

This study did not address behavioral changes and learning deficits in the mice following infection with $C$. pneumoniae. Although pathology was present in the brains of infected mice, the extent of damage would be comparable to that of amyloid over-expressing transgenic mice prior to the onset of substantial behavioral changes. Based on the assumption that chronic infection with $C$. pneumoniae results in a progressive accumulation of AD-like pathology, it is likely that following a longer infection with this organism, a greater degree of AD-like pathology such as NFTs may develop in the brains of these mice. The progressive accumulation of pathology presumably would lead to behavioral deficits in the infected mice. We are currently investigating whether longer courses of infection with $C$. pneumoniae would result in an increased accumulation of AD-like pathology.

\subsection{In conclusion}

This is the first report, of which we are aware, demonstrating that an infectious organism can trigger pathology in an animal brain consistent with Alzheimer's disease. The importance of this study is the demonstration that infection of mice through the olfactory pathways with $C$. pneumoniae, a respiratory pathogen, triggers amyloid pathology in the brain. The initiation of AD amyloid pathology in vivo, in an animal not genetically predisposed to the development of AD-like pathology, provides a unique model for the study of sporadic AD. Similar to humans that develop sporadic AD, but do not have any of the genetic mutations in the app, ps-1, and $p s-2$ genes, these mice exhibited early amyloid pathology, yet had no mutations in these genes. This model system induced the deposition of a progressive accumulation and maturation of mouse amyloid, not an overexpressed human protein. Following the infectious trigger, reactive astrocytes in some regions of the brain were associated with amyloid deposits as well. Over time, the mice infected with C. pneumoniae may also exhibit other characteristic neuropathology typical of AD such as NFTs. Although there are no obvious tangles at this early stage in the development of pathology, they may develop with prolonged exposure to the infectious agent. Thus, the experimental induction of AD-like pathology in young non-transgenic mice following infection with C. pneumoniae may parallel the early development of sporadic $\mathrm{AD}$.

\section{Acknowledgments}

We would like to thank the following individuals for their contributions to the work presented in this manuscript: Kevin Tomfohrde, D.O., Ms. Anna Gibbard, Ms. Gowri Harinarayanan, Ms. Anita Ketty, and Mr. David Steves.

\section{References}

[1] Airenne S, Surcel HM, Alakarppa H, Laitinen K, Paavonen J, Saikku $\mathrm{P}$, et al. Chlamydia pneumoniae infection in human monocytes [published erratum appears in Infect Immun 1999;67(12):6716]. Infect Immun 1999;67(3):1445-9.

[2] Bach JH, Chae HS, Rah JC, Lee MW, Park CH, Choi SH, et al. C-terminal fragment of amyloid precursor protein induces astrocytosis. J Neurochem 2001;78(1):109-20.

[3] Balin BJ, Gerard HC, Arking EJ, Appelt DM, Branigan PJ, Abrams JT, et al. Identification and localization of Chlamydia pneumoniae in the Alzheimer's brain. Med Microbiol Immunol (Berl) 1998;187(1):23-42.

[4] Boman J, Soderberg S, Forsberg J, Birgander LS, Allard A, Persson K, et al. High prevalence of Chlamydia pneumoniae DNA in peripheral blood mononuclear cells in patients with cardiovascular disease and in middle-aged blood donors. J Infect Dis 1998;178(1):274-7.

[5] Brodaty H. Realistic expectations for the management of Alzheimer's disease. Eur Neuropsychopharmacol 1999;9(suppl 2):S43-52.

[6] Brugg B, Dubreuil YL, Huber G, Wollman EE, Delhaye-Bouchaud $\mathrm{N}$, Mariani J. Inflammatory processes induce beta-amyloid precursor protein changes in mouse brain. Proc Natl Acad Sci USA 1995;92(7): 3032-5.

[7] Campbell S, Yates PS, Waters F, Richmond SJ. Purification of Chlamydia trachomatis by a simple and rapid filtration method. J Gen Microbiol 1991;137(Pt 7):1565-9.

[8] Carter DB, Dunn E, McKinley DD, Stratman NC, Boyle TP, Kuiper SL, et al. Human apolipoprotein E4 accelerates beta-amyloid deposition in APPsw transgenic mouse brain. Ann Neurol 2001;50(4):468-75.

[9] Corder EH, Saunders AM, Strittmatter WJ, Schmechel DE, Gaskell Jr PC, Rimmler JB, et al. Apolipoprotein E, survival in Alzheimer's disease patients, and the competing risks of death and Alzheimer's disease. Neurology 1995;45(7):1323-8.

[10] D'Andrea MR, Nagele RG, Gumula NA, Reiser PA, Polkovitch DA, Hertzog BM, et al. Lipofuscin and Abeta42 exhibit distinct distribution patterns in normal and Alzheimer's disease brains. Neurosci Lett 2002;323(1):45-9. 
[11] Gieffers J, Reusche E, Solbach W, Maass M. Failure to detect Chlamydia pneumoniae in brain sections of Alzheimer's disease patients. J Clin Microbiol 2000;38(2):881-2.

[12] Gordon MN, Holcomb LA, Jantzen PT, DiCarlo G, Wilcock D, Boyett KW, et al. Time course of the development of Alzheimer-like pathology in the doubly transgenic PS1 + APP mouse. Exp Neurol 2002; 173(2):183-95.

[13] Guenette SY, Tanzi RE. Progress toward valid transgenic mouse models for Alzheimer's disease. Neurobiol Aging 1999;20(2):20111.

[14] Hauss-Wegrzyniak B, Lukovic L, Bigaud M, Stoeckel ME. Brain inflammatory response induced by intracerebroventricular infusion of lipopolysaccharide: an immunohistochemical study. Brain Res 1998;794(2):211-24.

[15] Hilbich C, Kisters-Woike B, Reed J, Masters CL, Beyreuther K. Human and rodent sequence analogs of Alzheimer's amyloid beta A4 share similar properties and can be solubilized in buffers of $\mathrm{pH}$ 7.4. Eur J Biochem 1991;201(1):61-9.

[16] Hudson AP, Gerard HC, Whittum-Hudson JA, Appelt DM, Balin BJ. Chlamydia pneumoniae, APOE genotype, and Alzheimer's disease. In: Láge-Stehr J, editor. Chlamydia pneumoniae and chronic diseases. Berlin, Germany: Springer-Verlag; 2000. p. 121-36.

[17] Hyman BT, Van Hoesen GW, Kromer LJ, Damasio AR. Perforant pathway changes and the memory impairment of Alzheimer's disease. Ann Neurol 1986;20(4):472-81.

[18] Itzhaki RF, Lin WR, Shang D, Wilcock GK, Faragher B, Jamieson GA. Herpes simplex virus type 1 in brain and risk of Alzheimer's disease [see comments]. Lancet 1997;349(9047):241-4.

[19] Kaukoranta-Tolvanen SS, Laurila AL, Saikku P, Leinonen M, Liesirova L, Laitinen K. Experimental infection of Chlamydia pneumoniae in mice. Microb Pathog 1993;15(4):293-302.

[20] Kumar VB, Vyas K, Franko M, Choudhary V, Buddhiraju C, Alvarez J, et al. Molecular cloning, expression, and regulation of hippocampal amyloid precursor protein of senescence accelerated mouse (SAMP8). Biochem Cell Biol 2001;79(1):57-67.

[21] Laitinen K, Laurila AL, Leinonen M, Saikku P. Reactivation of Chlamydia pneumoniae infection in mice by cortisone treatment. Infect Immun 1996;64(4):1488-90.

[22] Lendon CL, Ashall F, Goate AM. Exploring the etiology of Alzheimer disease using molecular genetics. JAMA 1997;277(10): 825-31.

[23] Lim GP, Yang F, Chu T, Chen P, Beech W, Teter B, et al. Ibuprofen suppresses plaque pathology and inflammation in a mouse model for Alzheimer's disease. J Neurosci 2000;20(15):5709-14.

[24] Lue LF, Brachova L, Civin WH, Rogers J. Inflammation, A beta deposition, and neurofibrillary tangle formation as correlates of Alzheimer's disease neurodegeneration. J Neuropathol Exp Neurol 1996;55(10):1083-8.

[25] MacIntyre A, Abramov R, Hammond CJ, Little CS, Appelt DM, Balin BJ. Chlamydia pneumoniae infection of human brain endothelial cells and monocytes promotes the transmigration of monocytes through an in vitro blood brain barrier. J Neurosci Res 2003;71:740-50.

[26] MacIntyre A, Hammond CJ, Little CS, Appelt DM, Balin BJ. Chlamydia pneumoniae infection alters the junctional complex proteins of human brain microvascular endothelial cells. FEMS Microbiol Lett 2002;217(2):167-72.

[27] Mahony JB, Woulfe J, Munoz D, Browning D, Chong S, Smieja M. Identification of Chlamydiae pneumoniae in the Alzheimer's brain. World Alzheimer Congress 2000;7:1120.

[28] Malinverni R, Kuo CC, Campbell LA, Grayston JT. Reactivation of Chlamydia pneumoniae lung infection in mice by cortisone. J Infect Dis 1995;172(2):593-4.

[29] Miklossy J. Alzheimer's disease-a spirochetosis? Neuroreport 1993;4(7):841-8.

[30] Nochlin D, Shaw CM, Campbell LA, Kuo CC. Failure to detect Chlamydia pneumoniae in brain tissues of Alzheimer's disease. Neurology 1999;53(8):1888.

[31] Ossewaarde JM, Gielis-Proper SK, Meijer A, Roholl PJM. Chlamydia pneumoniae antigens are present in the brains of Alzheimer patients, but not in the brains of patients with other dementias. In: Saikku $\mathrm{P}$, editor. Proceedings of the 4th Meeting of European Society for Chlamydia Research, Helsinki, Finland; 20-23 August 2000. p. 284.

[32] Ring RH, Lyons JM. Failure to detect Chlamydia pneumoniae in the late-onset Alzheimer's brain. J Clin Microbiol 2000;38(7): 2591-4.

[33] Rosen GD, Williams AG, Capra JA, Connolly MT, Cruz B, Lu L, Airey DC, Kulkarni K, Williams RW. The Mouse Brain Library @ www.mbl.org. Int Mouse Genome Conference 2000; 14: 166. www.mbl.org.

[34] Roses AD. Apolipoprotein E alleles as risk factors in Alzheimer's disease. Annu Rev Med 1996;47:387-400.

[35] Rottenberg ME, Gigliotti Rothfuchs AC, Gigliotti D, Svanholm C, Bandholtz L, Wigzell $\mathrm{H}$. Role of innate and adaptive immunity in the outcome of primary infection with Chlamydia pneumoniae, as analyzed in genetically modified mice. J Immunol 1999;162(5):282936.

[36] Sturchler-Pierrat C, Abramowski D, Duke M, Wiederhold KH, Mistl $\mathrm{C}$, Rothacher S, et al. Two amyloid precursor protein transgenic mouse models with Alzheimer disease-like pathology. Proc Natl Acad Sci USA 1997;94(24):13287-92.

[37] Tanzi RE, Kovacs DM, Kim TW, Moir RD, Guenette SY, Wasco W. The gene defects responsible for familial Alzheimer's disease. Neurobiol Dis 1996;3(3):159-68.

[38] Williams R. Mapping genes that modulate mouse brain development: a quantitative genetic approach. In: Goffinet A, Rakic P, editors. Mouse brain development. New York: Springer; 2000. p. 21-49.

[39] Wilson CA, Doms RW, Lee VM. Intracellular APP processing and A beta production in Alzheimer disease. J Neuropathol Exp Neurol 1999;58(8):787-94.

[40] Wirths O, Multhaup G, Czech C, Feldmann N, Blanchard V, Tremp $\mathrm{G}$, et al. Intraneuronal APP/A beta trafficking and plaque formation in beta-amyloid precursor protein and presenilin-1 transgenic mice. Brain Pathol 2002;12(3):275-86.

[41] Wucherpfennig KW. Infectious triggers for inflammatory neurological diseases. Nat Med 2002;8(5):455-7.

[42] Yang ZP, Kuo CC, Grayston JT. A mouse model of Chlamydia pneumoniae strain TWAR pneumonitis. Infect Immun 1993;61(5): 2037-40. 